\title{
Descending threshold for ascending aortic aneurysmectomy: Is it time for a "left-shift" in guidelines?
}

Bulat A. Ziganshin, MD, PhD, Mohammad A. Zafar, MBBS, and John A. Elefteriades, MD, PhD (hon)

\section{ABSTRACT}

Current guidelines on the management of thoracic aortic disease recommend that the ascending aorta be replaced when it reaches the size of $5.5 \mathrm{~cm}$. Recently emerging data suggest that this criterion may need to be shifted to the left, signifying a recommendation to operate on patients with smaller aortic sizes. The data that support the need for a leftward shift in the guidelines include (1) novel and more granular data on the natural history of ascending aortic aneurysm between 5 and $6 \mathrm{~cm}$ showing that 2 hinge risk points exist-one at $5.25 \mathrm{~cm}$, and the other at $5.75 \mathrm{~cm}$; (2) aortic diameter before the moment of aortic dissection is at least $7 \mathrm{~mm}$ smaller than postdissection aortic size; (3) the advent of a semiautomated centerline method of imaging assessment seems to underestimate true ascending aortic size; (4) aortic surgery in the present era is very safe and its benefits outweigh the associated risks; (5) genetic testing via high-throughput next-generation sequencing identifies genetic defects responsible for aortic catastrophes at smaller aortic sizes; and (6) familial aortic dissection occurrence suggests that family members of an aortic dissection victim who harbor a sizable aneurysm should be operated on regardless of aortic size. (J Thorac Cardiovasc Surg 2019;157:37-42)

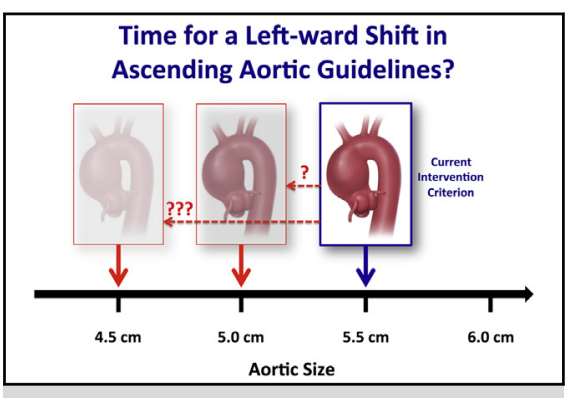

Is it time for a leftward shift in intervention criteria for ascending aortic aneurysm?

\section{Central Message}

Intervention criteria for ascending aortic aneurysm should be shifted leftward, recommending preemptive surgery at smaller aortic sizes.

\section{Perspective}

Six avenues of investigation-identification of novel risk hinge points in ascending aortic aneurysm, diameter change at instant of dissection, advent of the centerline imaging, increased safety of aortic surgery, advent of advanced genetic testing, and dire impact of previous familial aortic dissection-all argue in favor of a "left-shift," recommending prophylactic intervention at smaller aortic sizes.

See Editorial Commentary page 43.
The current US $^{1}$ and European ${ }^{2}$ guidelines on the management of thoracic aortic diseases (TADs) stipulate that the threshold for ascending aortic aneurysmectomy is $5.5 \mathrm{~cm}$, unless the patient has Marfan syndrome or other connective tissue disorder. The determination of appropriate intervention criteria is based on natural history studies of TAD. Our original studies, which recommended the $5.5-\mathrm{cm}$

\footnotetext{
From the Aortic Institute at Yale-New Haven Hospital, Yale University School of Medicine, New Haven, Conn.

Read at The American Association for Thoracic Surgery Aortic Symposium 2018, New York, New York, April 26-27, 2018.

Received for publication May 14, 2018; revisions received July 13, 2018; accepted for publication July 27, 2018.

Address for reprints: John A. Elefteriades, MD, PhD (hon), Aortic Institute at YaleNew Haven Hospital, Yale University School of Medicine, 789 Howard Ave, Clinic Building CB317, New Haven, CT 06519 (E-mail: john.elefteriades@yale.edu). $0022-5223 / \$ 36.00$

Copyright (c) 2018 by The American Association for Thoracic Surgery https://doi.org/10.1016/j.jtcvs.2018.07.114
}

criterion, were conducted more than 20 years ago. ${ }^{3-5}$ Recently, new data have emerged that suggest that the intervention criterion for ascending aortic aneurysm replacement may need to be shifted to the left, favoring prophylactic intervention at smaller ascending aortic dimensions. Here, we review 6 specific observations that, taken together, suggest that a "left-shift" in the intervention criteria for ascending aortic aneurysm may be appropriate.

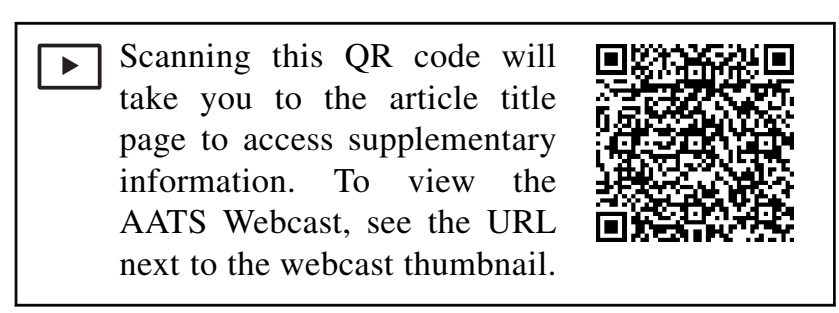




\section{Abbreviations and Acronyms}

$\mathrm{CT}=$ computed tomography

$\mathrm{TAD}=$ thoracic aortic disease

\section{Earlier Hinge Points in the Natural History of Ascending Aortic Aneurysm}

The early studies on the natural history of ascending and descending aortic aneurysm conducted at Yale were based on experience in approximately 230 patients. Our database

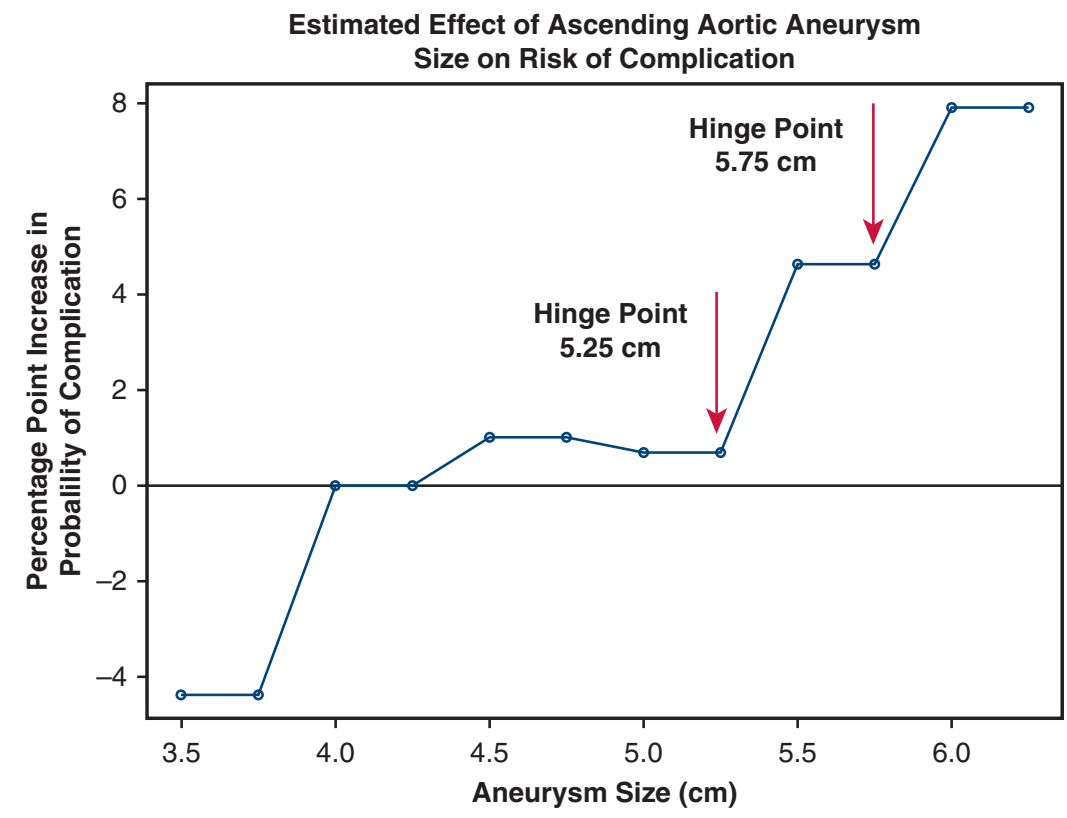

A

\begin{tabular}{|c|c|c|c|c|c|c|c|c|c|c|}
\hline & \multicolumn{10}{|c|}{ Aortic Size (cm) } \\
\hline & 3.5 & 4.0 & 4.5 & 5.0 & 5.5 & 6.0 & 6.5 & 7.0 & 7.5 & 8.0 \\
\hline $\begin{array}{l}\text { Height } \\
\text { (m) }\end{array}$ & & & & & & & & & & \\
\hline 1.40 & 2.50 & 2.86 & 3.21 & 3.57 & 3.93 & 4.29 & 4.64 & 5.00 & 5.36 & 5.71 \\
\hline 1.45 & 2.41 & 2.76 & 3.10 & 3.45 & 3.79 & 4.14 & 4.48 & 4.83 & 5.17 & 5.52 \\
\hline 1.50 & 2.33 & 2.67 & 3.00 & 3.33 & 3.67 & 4.00 & 4.33 & 4.67 & 5.00 & 5.33 \\
\hline 1.55 & 2.26 & 2.58 & 2.90 & 3.23 & 3.55 & 3.87 & 4.19 & 4.52 & 4.84 & 5.16 \\
\hline 1.60 & 2.19 & 2.50 & 2.81 & 3.13 & 3.44 & 3.75 & 4.06 & 4.38 & 4.69 & 5.00 \\
\hline 1.65 & 2.12 & 2.42 & 2.73 & 3.03 & 3.33 & 3.64 & 3.94 & 4.24 & 4.55 & 4.85 \\
\hline 1.70 & 2.06 & 2.35 & 2.65 & 2.94 & 3.24 & 3.53 & 3.82 & 4.12 & 4.41 & 4.71 \\
\hline 1.75 & 2.00 & 2.29 & 2.57 & 2.86 & 3.14 & 3.43 & 3.71 & 4.00 & 4.29 & 4.57 \\
\hline 1.80 & 1.94 & 2.22 & 2.50 & 2.78 & 3.06 & 3.33 & 3.61 & 3.89 & 4.17 & 4.44 \\
\hline 1.85 & 1.89 & 2.16 & 2.43 & 2.70 & 2.97 & 3.24 & 3.51 & 3.78 & 4.05 & 4.32 \\
\hline 1.90 & 1.84 & 2.11 & 2.37 & 2.63 & 2.89 & 3.16 & 3.42 & 3.68 & 3.95 & 4.21 \\
\hline 1.95 & 1.79 & 2.05 & 2.31 & 2.56 & 2.82 & 3.08 & 3.33 & 3.59 & 3.85 & 4.10 \\
\hline 2.00 & 1.75 & 2.00 & 2.25 & 2.50 & 2.75 & 3.00 & 3.25 & 3.50 & 3.75 & 4.00 \\
\hline 2.05 & 1.71 & 1.95 & 2.20 & 2.44 & 2.68 & 2.93 & 3.17 & 3.41 & 3.66 & 3.90 \\
\hline
\end{tabular}

Blue area indicates low risk, red area indicates moderate risk, green area indicates high risk and yellow area indicates severe risk.

B

FIGURE 1. A, Estimated probability of rupture or dissection of the ascending aorta by aneurysm size (The Y-axis represents the percentage point increase in "lifetime" probability of complications compared to baseline [between 4 and $4.25 \mathrm{~cm}$ ]). B, Yearly risk of complications (aortic dissection, rupture, and death) in patients with ascending aortic aneurysm as a function of aortic diameter (horizontal axis) and height (vertical axis). (Reprinted with permission from Zafar and colleagues. ${ }^{6}$ ) 
has now grown to 3400 patients. A recent analysis was performed on a large subset of this patient group. ${ }^{6}$ The increased patient number permitted much greater granularity of data. Specifically, in the region between 5 and $6 \mathrm{~cm}$, we have been able to discern now 2 separate hinge points-one at $5.25 \mathrm{~cm}$, and one at $5.75 \mathrm{~cm}$ (Figure 1). ${ }^{6}$ This more precise investigation of this critical aortic size range suggests that prophylactic surgery may need to be recommended at smaller aortic dimensions.

\section{Aortic Diameter Change at Moment of Dissection}

Another important point to consider is the sudden increase in the size of the aorta at the moment when dissection occurs, which was brought to attention by the University of Pennsylvania group. ${ }^{7,8}$ For most patients, the onset of dissection is the very first encounter with aortic diseaseand the very first time that the aorta is imaged and measured. However, new data indicate that this postdissection size is substantially larger than the true size of the aorta at the moment that the dissection occurred. Of necessity, we, the cardiothoracic surgical community, have been using an aortic size taken at the wrong time.

In fact, this phenomenon became known to us years ago, from animal studies with an experimental model of induced dissection. ${ }^{9}$ In those experiments, we had seen the aorta grow suddenly right in front of our eyes, but we had no way previously to evaluate this clinically. Recently, our group queried the large Yale Aortic Institute Database (3400 patients); we were able to identify several dozen patients who, by coincidence, happened to have had a computed tomography (CT) scan performed just before, but in close temporal proximity to, the day when their aortic dissection occurred. ${ }^{10}$ These patients provided invaluable data for evaluating the abrupt change in aortic size from the dissection itself. As seen from Figure 2, the predissection ascending aortic size was $7 \mathrm{~mm}$ smaller just before the dissection occurred. ${ }^{10}$ (In addition to simple pre- and postdissection size comparisons, we performed a regression analysis with "dissection event" as a variable. That analysis confirmed statistically the dramatic, immediate impact of dissection on aortic size.) This is also vividly illustrated in Video 1, of a patient who had $8 \mathrm{CT}$ scans before aortic dissection onset. The video shows the aorta growing very slowly (at about $1 \mathrm{~mm}$ per year) but then, at the time of aortic dissection, the aortic size increases dramatically, by $7 \mathrm{~mm}$. These important findings indicate that dissections are occurring at a much smaller size than previously thought—suggesting that a left-shift in our criteria for surgical intervention is necessary.

\section{Advent of Automated "Centerline" Imaging Measurement}

In recent years, a semiautomated method for evaluating aortic size, called the "centerline" CT, has gained

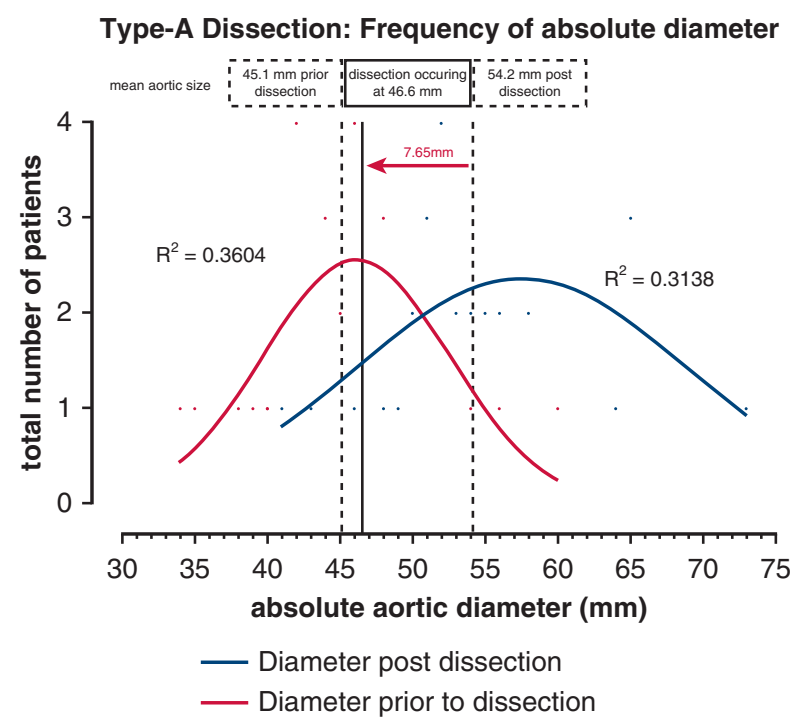

FIGURE 2. Frequency of aortic sizes before and at the time of aortic dissection. (Note: In addition to simple arithmetic calculations, regression methods using "aortic dissection" as a variable influencing size mitigated the impact of elapsed time between pre- and post-images.) (Based on data from Mansour and colleagues..$^{10}$ )

popularity ${ }^{11}$ for measurement of aortic size — not, however, without controversy. Concern has been expressed that centerline CT measurement underestimates aortic size. ${ }^{11-14}$ This has been our experience as well (J. Elefteriades, MD, unpublished data, April 2018). Both the literature and our as-yet unpublished studies have suggested that the centerline method under-reads diameter, compared with the traditional manual methods, by at least 3 to $4 \mathrm{~mm}$. These discrepancies in aortic size measurement between centerline and traditional methods merit closer investigation. Even proponents advise that the centerline method "... should be used with care considering its inherent limitations. Manually adjusted multiplanar reformations remain an essential tool for intuitive visualization of the vascular anatomy." 11

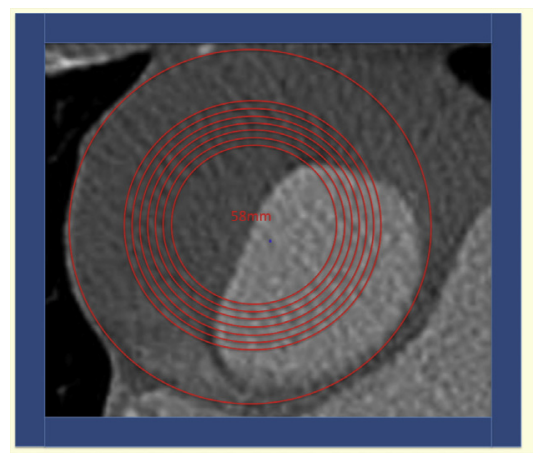

Patient 220

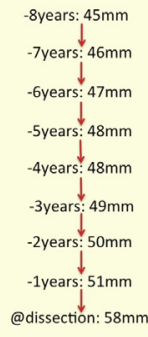

VIDEO 1. Eight consecutive yearly computed tomography scans of a single patient documenting the slow growth of the ascending aorta and a subsequent scan at time of aortic dissection. Video available at: https://www. jtcvs.org/article/S0022-5223(18)32822-8/fulltext. 


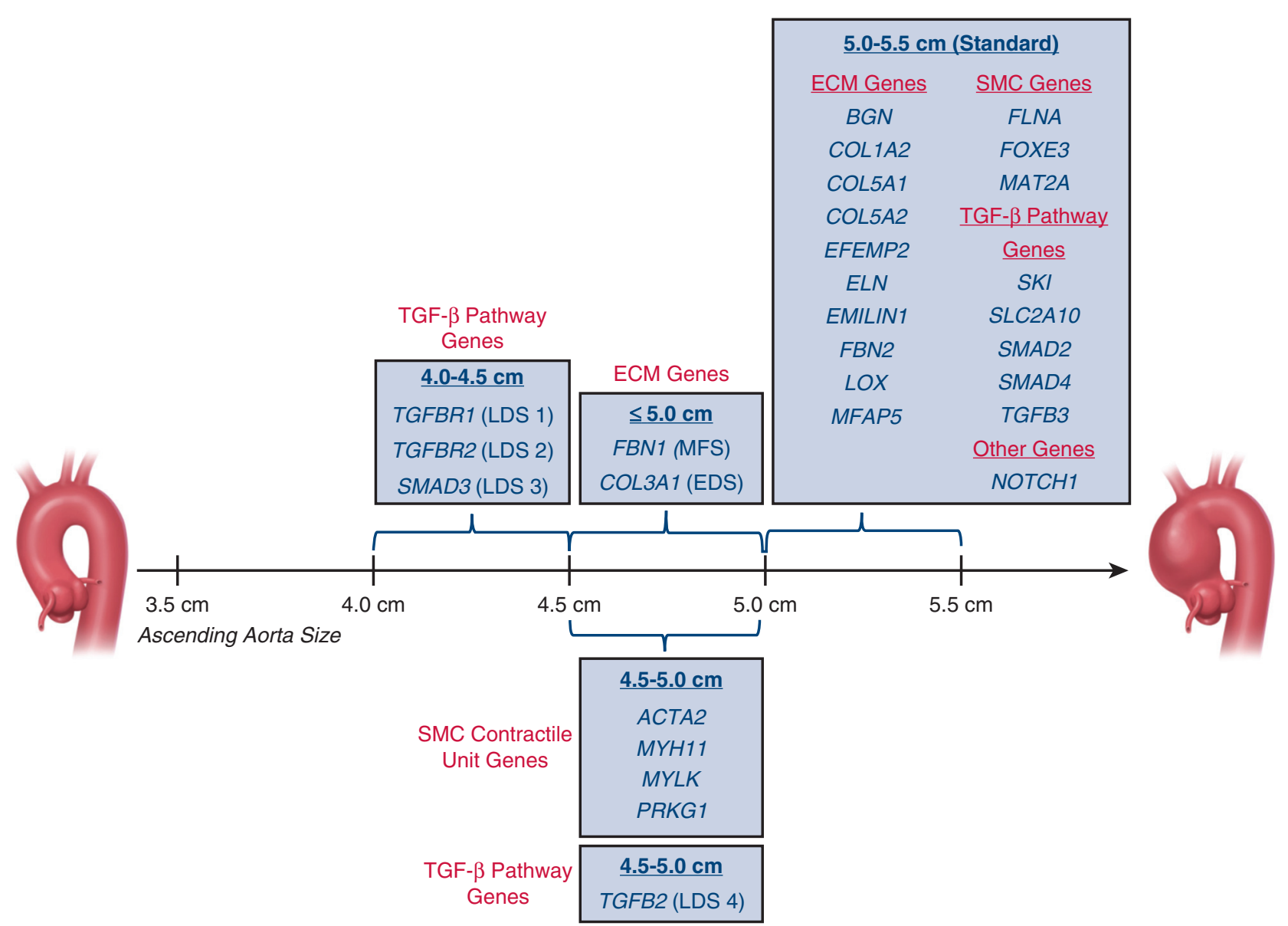

FIGURE 3. Simplified schematic illustration of ascending aorta dimensions for prophylactic surgical intervention divided by gene category: ECM genes, SMC contractile unit and metabolism genes, and TGF- $\beta$ signaling pathway genes. TGF- $\beta$, Transforming growth factor- $\beta ; E C M$, extracellular matrix; $M F S$, Marfan syndrome; $E D S$, Ehlers-Danlos syndrome; $S M C$, smooth muscle cell; $L D S$, Loeys-Dietz syndrome. (Reprinted with permission from Brownstein and colleagues. ${ }^{24}$ )

It is important to remember that the current intervention criteria were developed based on imaging data analysis before the advent of the centerline methodology (ie, via traditional manual axial, coronal, and sagittal image analysis; we measure ascending aortic diameter from axial images, selecting a vertical segment free of obliquity; we rely on the coronal images for assessment of transverse diameter of the aortic root segment). ${ }^{3-5}$ Thus, our intervention guidelines are not adapted to the use of the centerline measurement technique. We are concerned that the lower aortic diameter readings of the new centerline era may lead to undue delay of surgery in vulnerable patients. If centerline methods are to be accepted and used, it may be necessary to shift the intervention criterion to the left, to a smaller aortic size.

\section{Safety of Thoracic Aortic Surgery in the Present Era}

It is well established that decision making for pre-emptive aortic intervention depends on the balance between its benefit and its risk (eloquently discussed by Sundt ${ }^{15}$ ). At our center, we have reported the following operative mortality and postoperative stroke values (respectively): $1.9 \%$ and $1.4 \%$ for elective composite root replacement, ${ }^{16} 0 \%$ and $1.0 \%$ for elective root-sparing ascending aortic replacement, ${ }^{17}$ and $1.4 \%$ and $1.2 \%$ for elective aortic arch replacement. ${ }^{18}$ Similar excellent results are widely reported from experienced aortic centers nationally and internationally. (Note: It has been demonstrated that institutional volume has an important impact on operative outcomes in aortic surgery. ${ }^{19}$ The statements in this section about the suggested impact of increased surgical safety on the appropriate surgical criterion apply specifically to high-volume centers or operators with demonstrated safety records.) Such increased safety of aortic surgery in the present era likely further justifies a shift to the left of the criterion for surgical aortic intervention.

\section{Advent of Next-Generation Genetic Testing in Aortic Diseases}

It is becoming clear that syndromic TAD (with generalized findings beyond the aorta alone, as in Marfan, Ehlers-Danlos, and Loeys-Dietz syndromes) is only the tip of the genetic iceberg (explaining only approximately 
Time for a Left-ward Shift in Ascending Aortic Guidelines?

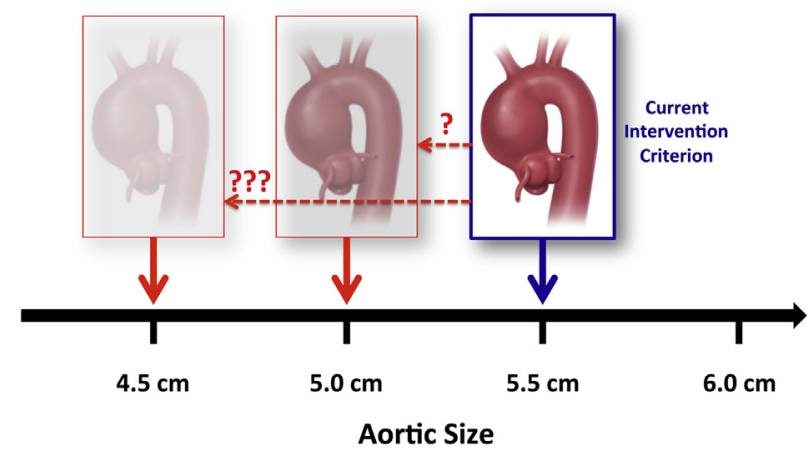

FIGURE 4. Is it time for a leftward shift in the intervention criteria for ascending aortic aneurysm?

$5 \%$ of all TAD cases). A much larger cross-section of patients with ascending aortic aneurysms have a familial pattern, without extra-aortic manifestations-now called "nonsyndromic familial aortic aneurysm."

Currently, next-generation genetic testing is gaining widespread popularity for patients with thoracic aortic aneurysm. Whole-exome sequencing and whole-genome sequencing have made such comprehensive testing fast and efficient at analyzing all of the genes implicated with TAD. ${ }^{20-23}$ In up to one third of cases, a documented disease-causing mutation (or a suspicious "variant of unknown significance") is identified. With such precise genetic information available, precision aortic care becomes possible. That is, whereas before all nonsyndromic aortic patients were placed into the same clinical "bucket," now patients with high-risk genotypes can be selected out for early surgery (such as those with MYLK, ACTA2, and MYH11 mutations, who may dissect at very small aortic sizes). We have arrived at an era of personalized aortic care. The "dictionary" of genetic aortic diseaseswhich describes specific clinical features and recommendations for each mutation-is growing rapidly. Figure 3 illustrates the current recommendations for surgical intervention for patients with specific aortic mutations. ${ }^{24}$ It is evident that many of the genetic aberrations will warrant intervention at smaller aortic size, also contributing to a leftward general shift in the overall guidelines. We recommend routine genetic screening for all patients with ascending aortic aneurysmsas meaningful results will be obtained in a substantial proportion of patients, permitting truly personalized aneurysm care based on the specific mutation or variant identified.

\section{Impact of Previous Aortic Dissection in a Family Member}

Previous clinical studies have documented that familial cases of TAD have a more malignant course, resulting in earlier disease onset and faster aortic growth rate, exemplifying a more aggressive clinical entity. ${ }^{25}$ Aortic specialists have long suspected that having a family history of aortic dissection, specifically, may increase the risk that family members may develop an aortic dissection as well. Our recent study has documented a dramatic impact of a previous dissection in a family member. ${ }^{26}$ Once there has been a known dissection in one family member, and another member of the same family is diagnosed with a sizable real aneurysm (we use $4 \mathrm{~cm}$ for this purpose), that patient faces a 3 -fold greater risk of dissection than in families without previous dissection. ${ }^{26}$ Thus, patients with a thoracic aortic aneurysm and family history of aortic dissection should probably undergo prophylactic aortic replacement almost regardless of aortic size, based just on proven family propensity to aortic dissection. ${ }^{26}$ Once again, this consideration is likely to warrant earlier intervention (left-shift) than the current criteria would indicate.

In the aforementioned discussions, items 1 to 4 regard a general left-shift in all ascending aortic aneurysm patients. Items 5 and 6 regard a left-shift specifically for patients with identified virulent aortic mutations found on whole-exome sequencing or a malignant family history of aortic dissection.

\section{CONCLUSIONS}

We can summarize as follows. We have looked at (1) the earlier ascending aortic hinge points in recent natural history analyses, (2) the smaller aortic size just before the dissection occurs, (3) the impact of the centerline method on absolute aortic measurements, (4) the low risk of aortic surgery in the present era, (5) the recent capability to select out patients with malignant genetic disorders for early surgery, and (6) the dramatic familial prognostic impact of a single previous dissection. The overall thrust of these findings suggests that in the future the criteria for elective aortic replacement many need to undergo a "left shift" (Figure 4).

Word of caution: As safety of aortic surgery is case volume dependent, we recommend that the "left-shift" to $5.0 \mathrm{~cm}$ proposed in this paper be selectively applied to high-volume centers or surgeons with demonstrated safety in performance of ascending surgery. Furthermore, the recommendation for "left-shift" should not be construed to apply to redo surgical cases, where the risk of operation will be greater.

\section{Webcast}

You can watch a Webcast of this AATS meeting presentation by going to: https://aats.blob.core.windows.net/media/ 18AO/26-br-1045-elefteriades-v2.mp4.

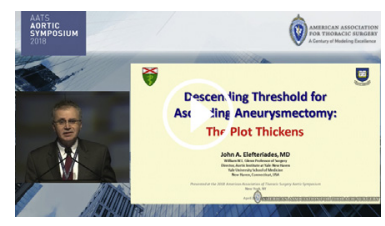




\section{Conflict of Interest Statement}

Authors have nothing to disclose with regard to commercial support.

\section{References}

1. Hiratzka LF, Bakris GL, Beckman JA, Bersin RM, Carr VF, Casey DE Jr, et al. 2010 ACCF/AHA/AATS/ACR/ASA/SCA/SCAI/SIR/STS/SVM guidelines for the diagnosis and management of patients with thoracic aortic disease. A Report of the American College of Cardiology Foundation/American Heart Association task force on practice guidelines, American Association for Thoracic Surgery, American College of Radiology, American Stroke Association, Society of Cardiovascular Anesthesiologists, Society for Cardiovascular Angiography and Interventions, Society of Interventional Radiology, Society of Thoracic Surgeons, and Society for Vascular Medicine. J Am Coll Cardiol. 2010;55: e27-129.

2. Erbel R, Aboyans V, Boileau C, Bossone E, Bartolomeo RD, Eggebrecht H, et al. 2014 ESC guidelines on the diagnosis and treatment of aortic diseases: document covering acute and chronic aortic diseases of the thoracic and abdominal aorta of the adult. The task force for the diagnosis and treatment of aortic diseases of the European Society of Cardiology (ESC). Eur Heart J. 2014;35:2873-926.

3. Coady MA, Rizzo JA, Hammond GL, Mandapati D, Darr U, Kopf GS, et al. What is the appropriate size criterion for resection of thoracic aortic aneurysms? J Thorac Cardiovasc Surg. 1997;113:476-91; discussion 489-91.

4. Davies RR, Goldstein LJ, Coady MA, Tittle SL, Rizzo JA, Kopf GS, et al. Yearly rupture or dissection rates for thoracic aortic aneurysms: simple prediction based on size. Ann Thorac Surg. 2002;73:17-27; discussion 27-8.

5. Davies RR, Gallo A, Coady MA, Tittle SL, Rizzo JA, Kopf GS, et al. Novel measurement of relative aortic size predicts rupture of thoracic aortic aneurysms. Ann Thorac Surg. 2006;81:169-77.

6. Zafar MA, Li Y, Rizzo JA, Charilaou P, Saeyeldin A, Velasquez CA, et al. Height alone, rather than body surface area, suffices for risk estimation in ascending aortic aneurysm. J Thorac Cardiovasc Surg. 2018; 155:1938-50.

7. Rylski B, Blanke P, Beyersdorf F, Desai ND, Milewski RK, Siepe M, et al. How does the ascending aorta geometry change when it dissects? J Am Coll Cardiol. 2014;63:1311-9.

8. Rylski B, Branchetti E, Bavaria JE, Vallabhajosyula P, Szeto WY, Milewski RK, et al. Modeling of predissection aortic size in acute type A dissection: more than $90 \%$ fail to meet the guidelines for elective ascending replacement. $J$ Thorac Cardiovasc Surg. 2014;148:944-8.e941.

9. Morales DL, Quin JA, Braxton JH, Hammond GL, Gusberg RJ, Elefteriades JA. Experimental confirmation of effectiveness of fenestration in acute aortic dissection. Ann Thorac Surg. 1998;66:1679-83.

10. Mansour AM, Peterss S, Zafar MA, Rizzo JA, Fang H, Charilaou P, et al. Prevention of aortic dissection suggests a diameter shift to a lower aortic size threshold for intervention. Cardiology. 2018;139:139-46.

11. Rengier F, Weber TF, Giesel FL, Bockler D, Kauczor HU, von Tengg-Kobligk H. Centerline analysis of aortic CT angiographic examinations: benefits and limitations. AJR Am J Roentgenol. 2009;192:W255-63.

12. Han SM, Elsayed RS, Ham SW, Mahajan A, Fleischman F, Rowe VL, et al. Comparison of intravascular ultrasound- and centerline computed tomographydetermined aortic diameters during thoracic endovascular aortic repair. $J$ Vasc Surg. 2017;66:1184-91.
13. Geisbüsch P, Liao W, Rohr K, Geisbüsch P, Liao W, Rohr K, et al. How precise are preinterventional measurements using centerline analysis applications? Objective ground truth evaluation reveals software-specific centerline characteristics. J Endovasc Ther. 2017;24:584-94.

14. Ahmed S, Zimmerman SL, Johnson PT, Lai H, Kawamoto S, Horton KM, et al. MDCT interpretation of the ascending aorta with semiautomated measurement software: improved reproducibility compared with manual techniques. J Cardiovasc Comput Tomogr. 2014;8:108-14.

15. Sundt TM. Aortic replacement in the setting of bicuspid aortic valve: how big? How much? J Thorac Cardiovasc Surg. 2015;149:S6-9.

16. Mok SC, Ma WG, Mansour A, Charilaou P, Chou AS, Peterss S, et al. Twentyfive year outcomes following composite graft aortic root replacement. J Card Surg. 2017;32:99-109.

17. Peterss S, Charilaou P, Dumfarth J, Li Y, Bhandari R, Tranquilli M, et al. Aortic valve disease with ascending aortic aneurysm: impact of concomitant rootsparing (supracoronary) aortic replacement in nonsyndromic patients. J Thorac Cardiovasc Surg. 2016;152:791-8.e791.

18. Ziganshin BA, Rajbanshi BG, Tranquilli M, Fang H, Rizzo JA, Elefteriades JA. Straight deep hypothermic circulatory arrest for cerebral protection during aortic arch surgery: safe and effective. J Thorac Cardiovasc Surg. 2014;148:888-98; discussion 898-900.

19. Hughes GC, Zhao Y, Rankin JS, Scarborough JE, O'Brien S, Bavaria JE, et al. Effects of institutional volumes on operative outcomes for aortic root replacement in North America. J Thorac Cardiovasc Surg. 2013;145:166-70.

20. Ziganshin BA, Bailey AE, Coons C, Dykas D, Charilaou P, Tanriverdi LH, et al. Routine genetic testing for thoracic aortic aneurysm and dissection in a clinical setting. Ann Thorac Surg. 2015;100:1604-11.

21. Wooderchak-Donahue W, VanSant-Webb C, Tvrdik T, Plant P, Lewis T, Stocks J, et al. Clinical utility of a next generation sequencing panel assay for Marfan and Marfan-like syndromes featuring aortopathy. Am J Med Genet A. 2015;167A: 1747-57.

22. Poninska JK, Bilinska ZT, Franaszczyk M, Michalak E, Rydzanicz M, Szpakowski E, et al. Next-generation sequencing for diagnosis of thoracic aortic aneurysms and dissections: diagnostic yield, novel mutations and genotype phenotype correlations. J Transl Med. 2016;14:115.

23. Weerakkody R, Ross D, Parry DA, Ziganshin B, Vandrovcova J, Gampawar P, et al. Targeted genetic analysis in a large cohort of familial and sporadic cases of aneurysm or dissection of the thoracic aorta. Genet Med. March 15, 2018 [Epub ahead of print].

24. Brownstein AJ, Ziganshin BA, Kuivaniemi H, Body SC, Bale AE, Elefteriades JA. Genes associated with thoracic aortic aneurysm and dissection: an update and clinical implications. Aorta (Stamford). 2017;5: $11-20$.

25. Albornoz G, Coady MA, Roberts M, Davies RR, Tranquilli M, Rizzo JA, et al. Familial thoracic aortic aneurysms and dissections-incidence, modes of inheritance, and phenotypic patterns. Ann Thorac Surg. 2006;82:1400-5.

26. Ma WG, Chou AS, Mok SCM, Ziganshin BA, Charilaou P, Zafar MA, et al. Positive family history of aortic dissection dramatically increases dissection risk in family members. Int J Cardiol. 2017;240:132-7.

Key Words: aneurysm, thoracic aortic aneurysm, criterion, aortic dissection, whole-exome sequencing, CT scan 